\begin{tabular}{|c|c|}
\hline Title & Out-of-Plane Stability of Buckling-Restrained Braces Placed in Chevron A rrangement \\
\hline Author(s) & Hikino, Tsuyoshi; Okazaki, Taichiro; Kajiwara, Koichi; Nakashima, Masay oshi \\
\hline Citation & $\begin{array}{l}\text { Journal of Structural Engineering, 139(11), 1812-1822 } \\
\text { https://doi.org/10.1061/A SCE)ST.1943-541X .0000767 }\end{array}$ \\
\hline Issue Date & $2013-11$ \\
\hline DOC URL & http:/hdl. handle.net/2115/54933 \\
\hline Rights & $\begin{array}{l}\text { This material may be downloaded for personal use only. A ny other use requires prior permission of the A merican } \\
\text { Society of Civil Engineers }\end{array}$ \\
\hline Type & article (author version) \\
\hline File Information & Stability of BRBs- HUSCAP.pdf \\
\hline
\end{tabular}

Instructions for use 


\title{
Out-of-Plane Stability of Buckling-Restrained Braces Placed in a Chevron Arrangement
}

\author{
Tsuyoshi Hikino ${ }^{1}$; Taichiro Okazaki, A.M.ASCE ${ }^{2}$; Koichi Kajiwara ${ }^{3}$; and \\ Masayoshi Nakashima, M.ASCE ${ }^{4}$
}

\begin{abstract}
Large-scale shake table tests were performed at E-Defense, Japan, to examine the out-of-plane stability of buckling-restrained braces (BRBs). Two specimens were subjected repeatedly to a near-fault ground motion with increasing amplification. The test specimens comprised a single-bay, single-story steel frame and a pair of BRBs placed in a chevron arrangement. The specimens were not braced at the brace-to-beam intersection in order to produce a condition where the BRBs are susceptible to out-of-plane instability. Standard BRBs were used in the first specimen, while BRBs with a flexible segment at each end of the steel core were used in the second specimen. A simple stability model predicted the BRBs in the second specimen to fail due to out-of-plane buckling. The first specimen exhibited excellent ductility during the shake table tests, while the second specimen developed severe out-of-plane deformation that compromised the ductility of BRBs. Based on the experimental observations and the stability model, a methodology is proposed to evaluate bracing requirements at the braceto-beam intersection.
\end{abstract}

Keywords Shake table tests; Steel frames; Seismic design; Bracing; Lateral stability.

\footnotetext{
${ }^{1}$ Manager, Nippon Steel and Sumikin Engineering Co. Ltd., Shinagawa, Tokyo 141-8604, Japan. (formerly researcher at National Research Institute for Earth Science and Disaster Prevention). E-mail: hikino.tsuyoshi@eng.nssmc.com

${ }^{2}$ Associate Professor, Graduate School of Engineering, Hokkaido University, Sapporo, Hokkaido 060-8628, Japan. (formerly researcher at National Research Institute for Earth Science and Disaster Prevention) . E-mail: tokazaki@eng.hokudai.ac.jp

${ }^{3}$ Director of Hyogo Earthquake Engineering Research Center (E-Defense), National Research Institute for Earth Science and Disaster Prevention, Miki, Hyogo 673-0515, Japan.

${ }^{4}$ Professor, Disaster Prevention Research Institute, Kyoto University, Gokasho, Uji, Kyoto 611-0011, Japan.
} 


\section{Introduction}

Buckling-restrained braces (BRBs) refer to a class of axially loaded members that achieve stable inelastic behavior under both tension and compression (AISC 2005a; Uang and

Nakashima 2004). A BRB comprises a steel core and a buckling-restraining system that controls flexural and local buckling of the steel core. The design intention is to allow axial forces to be carried solely by the ductile steel core. In many commercialized products, buckling restraint is achieved by casing the steel core inside a mortar-filled steel tube, and by limiting shear transfer between the steel core and mortar with adequate clearance and unbonding material. The US practice has incorporated BRBs into a new category of concentrically braced frames (CBFs), named buckling-restrained braced frames (BRBFs), that exhibits superior ductility over conventional CBFs (AISC 2005a).

The stable and predictable cyclic behavior of BRBs has been demonstrated by numerous tests (e.g. Saeki et al. 1995; Black et al. 2004). In the U.S., the AISC Seismic Provisions (AISC 2005a) assure reliable performance of BRBs by a qualifying test requirement. On the other hand, recent BRBF system tests indicate that the performance of BRBs can be affected significantly by interaction with the surrounding framing elements and detailing of the bracing connection. For example, tests by Mahin et al. (2004) and Roeder et al. (2006) suggest that local buckling and distortion of framing elements associated with large drifts can cause severe out-of-plane rotation of the gusset plates. Tests by Chou and Chen (2009) suggest that the stable inelastic behavior of BRBs can be compromised by out-of-plane buckling of gusset plates. Fahnestock et al. (2007) proposed a framing connection detail that shields the BRB bracing connection from moment frame action, and thereby, precludes out-of-plane distortion of the system. 

as a limit state independent of frame deformation or gusset plate buckling. Tembata et al. (2004), Kinoshita et al. (2007), and Takeuchi et al. (2009) derived a comprehensive set of analytical solutions to the out-of-plane stability problem of BRBs, and validated the solutions with static, cyclic loading tests. Takeuchi et al. $(2004 ; 2009)$ and Kinoshita et al. (2008) investigated the rotational stiffness of BRBs and its bracing connections, respectively, acknowledging these stiffness values to be key factors that control the out-of-plane stability of BRBs. Koetaka and Kinoshita (2009) provide a review of the Japanese literature and propose general design criteria to control out-of-plane buckling of BRBs placed in a chevron or single-diagonal arrangement. shown in Fig. 1(a), require special attention for out-of-plane stability. For chevron BRBFs, the AISC Seismic Provisions (2005a) require both flanges of the beam to be braced at the BRB-tobeam intersection unless the beam provides the required brace horizontal strength, $P_{b r}$, and stiffness, $\beta$, defined as follows:

$$
\begin{aligned}
& P_{b r}=0.01 P_{r} \\
& \beta=\frac{1}{0.75}\left(\frac{8 P_{r}}{L_{b}}\right)
\end{aligned}
$$
In the above equations, $P_{r}$ is the compressive strength of the $\mathrm{BRB}, L_{b}$ is the length of the BRBs, and 0.75 is the resistance factor. Equations (1) and (2) express the column nodal bracing requirements (AISC 2005b). It is not clear whether the out-of-plane stability of BRBs noted by the Japanese studies may be controlled by these requirements. 
dynamic loading condition, and to examine how BRBs may behave after out-of-plane instability occurs. As a key component of this program, large-scale shake table tests were conducted at EDefense, a three-dimensional, large-scale earthquake testing facility maintained and operated by the National Research Institute for Earth Science and Disaster Prevention of Japan. This paper reviews the stability problem reported in earlier Japanese studies, describes analytical solutions to a stability model that simplifies the previous models in the Japanese literature. The shake-table test program and its design implications are discussed. Finally, the stability model is extended to include out-of-plane imperfection and drift, and used to describe bracing requirements for beams in chevron BRBFs.

\section{Stability Model}

The following five assumptions are introduced to derive an analytical expression for the out-of-plane buckling strength of BRBs placed in a chevron arrangement as shown in Fig. 1(a).

1) Out-of-plane stability of BRBs is controlled by the forces and deformation produced in the plane that includes the BRB and that is perpendicular to the frame. The stability problem is not influenced by in-plane framing action or tension in the opposite BRB.

2) The steel core of the BRBs includes short, unrestrained segments outside of the yielding segment at the termination of stiffeners. The unrestrained segments have negligible flexural out-of-plane stiffness compared to any other segment of the BRB.

3) Yielding occurs only in the yielding segment of the steel core while all other components remain elastic. Further, because of adequate stiffening, distortion of the gusset plates and the beam section is negligibly small. 
4) The BRBs are adequately designed such that flexural buckling or local buckling of the steel core does not control the strength of the BRB.

5) Initial imperfection and out-of-plane drift is neglected.

Fig. 1(b) shows a first-order, out-of-plane buckling model of the BRB based on the five assumptions. The model comprises rigid elements, internal hinges, and elastic end restraints. Internal hinges are placed in the steel core per assumption (2). The top end of the buckling model is the point of intersection between the BRB and the beam. The bottom of the system represents the brace-beam-column node that is well braced, and is hence modeled as rigid. This model is a simplification of the elastic-perfectly plastic model proposed by Tembata et al. (2004) and Kinoshita et al. (2007), shown in Fig. 1(c), which accounts for elastic deformation of the gusset plates, and whose solutions are described in Appendix A.

Figs. 2(a) and (b) illustrate common bracing connections employed for BRBs in Japan which are believed to satisfy assumption (3). Both connections provide substantial restraint for out-of-plane rotation. Fig. 2(c) shows an alternative detail where the fin plates (stiffener plates oriented perpendicular to the gusset plate) are not welded directly to the beam flanges and where the gusset plates are not stiffened along the edges. Such connections are commonly used in the US practice. This relatively flexible bracing connection does not justify assumption (3), and thereby the buckling model shown in Fig. 1(d) may be more adequate (Takeuchi et al. 2009). The models in Fig. 1(b) to (d) represent BRBF design that accommodates out-of-plane deformation by controlled rotation of elements. AIJ (2009) suggests two options to permit rotation either in the BRBs or in the bracing connections. This study adopts the former option through assumption (2). 

the horizontal and rotational stiffness supplied at the top end of the BRB, $K_{\mathrm{H}}$ and $K_{\mathrm{R}}$, and two length measurements $L_{1}$ and $L_{2}$. The spring constants may be evaluated based on the flexural and torsional stiffness of the beam and the properties of lateral braces placed at the BRB-to-beam intersection. As shown in Fig. 3(a), the buckling modes may be described in terms of three displacement parameters $\theta_{1}, \theta_{2}$, and $u$, of which two are independent. From the equilibrium condition, the critical load, $P_{\mathrm{cr}}$, is determined as the smaller solution to the following quadratic equation.

$$
\left(P-P_{H}\right)\left(P-P_{R}\right)-P \cdot\left(\frac{L_{1}}{L_{2}} P_{H}\right)=0
$$

94 In the above equation:

$$
P_{H}=K_{H} \cdot L_{2} \quad P_{R}=\frac{K_{R}}{L_{1}}
$$

Fig. 3(b) and (c) illustrate limit cases. For Case 1, when the rotational spring is infinitely rigid $\left(\theta_{1}=0, u=L_{2} \theta_{2}\right)$, the critical load is $P_{1}=P_{H}$. For Case 2 , when the translational spring is infinitely rigid $\left(u=0, \theta_{1} / \theta_{2}=L_{2} / L_{1}\right)$, the critical load, $P_{2}$, is expressed as follows:

$$
P_{2}=P_{R} \frac{L_{2}}{L_{1}+L_{2}}
$$

Appendix A shows that the above solution is a special case of the solution derived by Kinoshita et al. (2007). Fig. 4 plots the combinations of $P_{1}$ and $P_{2}$ that achieves $P_{c r}=P_{0}$, where $P_{0}$ is the compressive strength of the steel core. The domain in the $P_{1}-P_{2}$ space above the curve and opposite the origin defines the safe domain where the buckling strength is greater than $P_{0}$, 

and thus out-of-plane buckling of the BRB may be avoided. The curves are plotted for $L_{1} / L_{2}=$ 0.25 and 0.5 . The case $L_{1} / L_{2}=0.25$ may represent BRBs with compact bracing connections, while $L_{1} / L_{2}=0.5$ may represent BRBs with larger bracing connections that uses bolted splices as shown in Fig. 2.

The buckling mode is expressed as follows.

$$
\frac{\theta_{1}}{\theta_{2}}=\frac{P_{H}}{P_{R}-P_{c r}+\frac{L_{1}}{L_{2}} P_{H}}=\frac{P_{H}-P_{c r}}{\frac{L_{1}}{L_{2}} P_{H}} \quad \text { or } \quad \frac{u}{L_{1} \theta_{1}}=\frac{P_{c r}}{P_{H}-P_{c r}}
$$

Equation (6) indicates that Case 1 controls (i.e., $\theta_{1} \approx 0$ ) when $P_{2}$ is significantly greater than $P_{1}$ and thus $P_{c r} \approx P_{1}$, while Case 2 controls (i.e., $u \approx 0, \theta_{1} / \theta_{2} \approx L_{2} / L_{1}$ ) when $P_{1}$ is significantly greater than $P_{2}$ and thus $P_{c r} \approx P_{2}$.

\section{Test Plan}

Two large-scale specimens were subjected to a series of strong earthquake ground motions to examine whether out-of-plane buckling of BRBs can be predicted based on the analytical solutions described above, and to examine how BRBs may behave after out-of-plane instability occurs.

\section{Specimens}

Two braced frame specimens were tested in this program. Fig. 5(a) shows the specimen comprising a built-up wide-flange beam, two cold-formed square-HSS columns, and a pair of BRBs. The 4.15-m span and 2.10-m height corresponds to a 70\%-scale building structure. After Specimen 1 was tested, the BRBs were replaced by a new pair of BRBs to prepare Specimen 2. 
The standard through-diaphragm detail (Nakashima et al. 2000) was used to achieve rigid beam-

121 to-column connections. The bracing connections adopted the standard detail shown in Fig. 2(a) that welds the fin plates directly to the beam. The beam is provided with stiffeners at the BRBto-beam intersection to control local beam distortion. The columns were rigidly connected to the shake table via stiff base beams. Table 1 lists the Japanese Industry Standards (JIS) designation and measured mechanical properties for each material used to fabricate the specimen. The specified minimum yield strength is 235,295 , and $325 \mathrm{MPa}$, respectively, for SN400, BCR295, and SM490 steel. At the top side of the specimen, each end of the beam was connected to the test-bed system (described later) through a pin-ended load cell. The specimen was laterally braced along the columns and beam at discrete locations indicated in Fig. 5(a) by " $\times$ " marks. No bracing was provided at the middle segment of the beam (between points $\mathrm{B}$ and $\mathrm{D}$ ) to intentionally reduce the torsional and translational restraint at the BRB-to-beam intersection.

The two specimens were nominally identical except for the BRBs. As shown in Fig. 5(b) and $(\mathrm{c})$, the BRBs used a $74 \times 12 \mathrm{~mm}$ plate for the steel core and a square-HSS $125 \times 125 \times 2.3$ mm casing filled with mortar for the buckling-restraining system. The key difference between the BRBs was the embedment length of the stiffened segment (the transition segment) inside the steel casing. An experimental study by Takeuchi et al. (2009) suggest that, if the embedment length exceeds 1.5 to 2 times the width of the yielding segment, then no local reduction in flexural stiffness occurs along the length of the steel core. While Specimen 1 used an embedment length exactly at the minimum requirement by Takeuchi et al. (Fig. 5(b) indicates $110 \mathrm{~mm}$ ), Specimen 2 used a much shorter embedment length (Fig. 5(c) indicates $30 \mathrm{~mm}$ ) to represent a least favorable BRB design for out-of-plane stability. The BRBs were oriented with the flat plate steel core parallel to the plane of the frame. The parallel orientation is more commonly adopted 
than the orthogonal orientation, and represents a less favorable condition for out-of-plane stability. Because rotational stiffness at the end of the yielding segment is developed by bearing between the transition segment and mortar, and the yielding segment itself possesses limited rotational stiffness, the shorter embedment length in Specimen 2 was expected to promote outof-plane instability of the BRBs. In other words, assumption (2) of the stability model in Fig. 1(b) is valid for Specimen 2 but it is not valid for Specimen 1. Out-of-plane buckling of BRBs was not likely to occur in Specimen 1.

Assuming that BRB buckling does not occur, a rigid-plastic analysis using the measured material properties estimated the lateral strength of the specimen to be $798 \mathrm{kN}$, at which stage the BRBs and underlying moment frame provide 58 and $42 \%$, respectively, of the lateral strength.

\section{Stability Design Check}

The spring constants $K_{\mathrm{H}}$ and $K_{\mathrm{R}}$ shown in Fig. 1(b) are determined by the weak-axis bending stiffness and torsional stiffness, respectively, of the beam. Elastic analysis assuming the beam to be simply supported at the intermediate bracing points (B and D in Fig. 5) and fixed at the face of the columns (A and E) for weak-axis bending and torsion, leads to $K_{\mathrm{H}}=6,070 \mathrm{kN} / \mathrm{m}$ and $K_{\mathrm{R}}=260 \mathrm{kN} \cdot \mathrm{m} / \mathrm{rad}$. Using $L_{1}=0.825 \mathrm{~m}$ and $L_{2}=1.41 \mathrm{~m}$ (see Fig. 5), Equations (3) to (5) give $P_{1}=8,560 \mathrm{kN}, P_{2}=199 \mathrm{kN}$, and $P_{\mathrm{cr}}=197 \mathrm{kN}$. While $P_{1}$ is substantially larger than the

160 yield strength of the steel core based on the measured yield strength, $P_{y}=264 \mathrm{kN}, P_{2}$ and $P_{\text {cr }}$ are

161 smaller than $P_{y}$. Therefore, the stability model suggests the BRBs to buckle out of plane before

162 developing their yield strength in compression, and suggests the buckling mode to be dominated 163 by limit case 2 . 
defined by Equations (1) and (2) is $P_{b r}=4.0 \mathrm{kN}$ and $\beta=1,380 \mathrm{kN} / \mathrm{m}$. Because $P_{b r}$ is very easily exceeded by the weak-axis bending strength of the beam and $K_{\mathrm{H}}$ is more than four times larger than $\beta$, the AISC Seismic Provisions (AISC 2005a) do not require lateral bracing at the middle of the beam. In other words, neither specimen violates the AISC Seismic Provisions.

\section{Test Bed}

The specimens were subjected to ground shaking at the E-Defense facility using the "test bed" system developed by Takeuchi et al. (2008). The test beds are multi-purpose devices that supply horizontal mass to the specimen while adding minimal lateral force resistance. As shown in Fig. 6, a pair of test beds was used for this program, with one placed at each side of the specimen. At the base, the test bed was connected to the shake table through a set of linear bearings which produced minimal friction (friction coefficient was estimated as 0.0033 by Takeuchi et al. (2008)) for motion in the loading plane, and which restrained out-of-plane and vertical motion. At the top, the test bed was connected to each end of the specimen, with a load cell placed in both load paths. The two test beds and additional test rigs supplied a combined 69.4-metric ton mass to the specimen. The test bed was also used to anchor the out-of-plane bracing indicated in Fig. 5(a). Consequently, the test beds were arranged to permit planar motion of the planar specimen. The scaling rules are summarized in Table 2 where $\lambda$ indicates the scaling factor for length. For this test, $\lambda=0.7$ and time and stress were not scaled.

\section{Test Procedure}

The East-West component of the JR Takatori motion from the 1995 Kobe earthquake (Nakamura et al. 1996) was introduced in the direction parallel to the primary plane of the 
specimen. The EW component is characterized by a peak acceleration of $6.6 \mathrm{~m} / \mathrm{s}^{2}$ and strong velocity pulses. Fig. 7 shows the response acceleration spectrum obtained for $5 \%$ of critical damping $(\zeta=0.05)$. The spectral response was between 17 and $23 \mathrm{~m} / \mathrm{s}^{2}$ for periods between 0.15 and 0.4 seconds, while the natural vibration period of the specimen was predicted as $0.2 \mathrm{sec}$. Therefore, the JR Takatori motion was twice as large as the standard response spectrum for bedrock specified in Japan (BCJ 2012). The shake table tests were conducted by introducing the motion repeatedly with increasing amplification. Table 3 lists the target amplification levels. Specimen 1 was tested with nine excitations, targeting between 14 and $120 \%$ of the JR Takatori EW motion. Specimen 2 was tested with seven excitations, targeting between 14 and $150 \%$ of the JR Takatori EW motion, with the $28 \%$ motion introduced twice. Elastic analysis suggested $28 \%$ to be the minimum scale factor for the BRBs to reach the critical compressive strength $P_{c r}$.

\section{Instrumentation}

The load cells indicated in Fig. 6 were used to measure story shear. Displacement transducers were used to measure the story drift and the out-of-plane deformation of the beam and BRBs. The force distributions in the beam, columns, and BRBs were evaluated based on strain gauges placed at selected sections of the beam and columns. Elongation of the BRB steel core was measured from the change in relative distance between the end of steel casing and core projection of the BRB. Data was collected at a rate of 1,000 Hz. All data was passed through a low-pass filter to eliminate frequency content above $50 \mathrm{~Hz}$.

\section{Test Results}

Based on unidirectional white noise excitation, the natural vibration period was 
determined as $0.18 \mathrm{sec}$ for Specimen 1 and $0.19 \mathrm{sec}$ for Specimen 2. The period was equivalent to that of a single or two story building. The damping ratio was evaluated as 0.03 . Damping was produced primarily by friction in the linear bearings supporting the test bed.

Table 3 lists the maximum measured acceleration of the shake table. The table also lists

211 the response spectral acceleration (RSA) averaged over a period range of 0.17 to 0.2 seconds,

212 evaluated from the measured table motion and assuming a damping ratio $\zeta=0.03$. The

213 corresponding values for the $100 \%$ target motion were $6.56 \mathrm{~m} / \mathrm{s}^{2}$ and $29 \mathrm{~m} / \mathrm{s}^{2}$, respectively. The

214 listed values indicate that the table motion was amplified as targeted.

Both specimens exhibited very similar response up to the $70 \%$ motion. Fig. 8 compares the story shear versus drift ratio response of the two specimens to the 100 and $120 \%$ motions.

217 The drift ratio was evaluated as the relative displacement measured between the beam and base 218 beam divided by the story height of $2.1 \mathrm{~m}$. Specimen 1 exhibited very stable and ductile behavior 219 even under the largest 120\% motion, developing a maximum drift of $0.014 \mathrm{rad}$. and leaving a residual drift smaller than $0.001 \mathrm{rad}$. Minimal yielding was observed in the framing members 221 after testing of Specimen 1 was completed. On the other hand, Specimen 2 experienced substantial degradation in elastic stiffness during motions $100 \%$ and larger, and recorded a maximum drift ratio of 0.016 rad. during the $100 \%$ motion and $0.032 \mathrm{rad}$. during the $120 \%$ motion. Fig. 9 shows the maximum and residual drift ratios measured from each motion. The figure indicates very similar response of the two specimens under motions up to $70 \%$. The $100 \%$ and larger motions caused minimal damage to Specimen 1 but severe damage to Specimen 2.

227 While the $150 \%$ motion produced large drift ratios for Specimen 2 ranging between -0.06 and $2280.025 \mathrm{rad}$, this motion left a fairly small residual drift of $-0.012 \mathrm{rad}$. 
Fig. 10 shows photographs of Specimen 2 taken between the 120 and $150 \%$ motions. Fig. 10(a) views the elevation of the specimen from an angle. Kinking deformation is seen at the top and bottom ends of both BRBs, between the core projection and steel casing. The kink rotation angle was notably larger at the top end of the BRB than at the bottom end, and the direction of kink rotation is opposite between the top and bottom. Inelastic torsional deformation is seen in the beam. Fig. 10(b) is a close-up view of the middle portion of the beam and the top ends of the two BRBs. The close-up view indicates that the kinking deformation of the BRBs was accommodated by twisting of the beam. The deformation seen in the photos is very similar to the buckling mode for limit case 2 shown in Fig. 3(c). Although not visible in the photos, the steel casing was bulged outward at the side which the transition segment bore against.

Fig. 11 further compares the two specimens from the $100 \%$ motion, plotting the elongation of the BRB steel core, kink rotation at the top and bottom ends of the $\mathrm{BRB}\left(\theta_{1}+\theta_{2}\right.$ and $\theta_{2}$ in Fig. 3), twist angle of the beam at the BRB-to-beam intersection $\left(\theta_{1}\right)$, and lateral translation of the beam at the BRB-to-beam intersection $(u)$, respectively, against the BRB tension. The response is shown for the West BRB which was placed on the closer side as viewed in Fig. 10. The behavior of the East BRB was symmetric to the West BRB. Positive rotation and twist are taken in the counter-clockwise direction as viewed in Fig. 10, while positive beam translation is taken in the left-to-right direction. The broken horizontal lines indicate the yield 247 strength of the steel core based on the measured yield strength, $P_{y}=264 \mathrm{kN}$. The solid horizontal 248 lines indicate the critical compressive strength, $P_{\mathrm{cr}}=197 \mathrm{kN}$, which applies only to Specimen 2. 249 The maximum tensile and compressive force was 1.24 and $1.19 P_{y}$, respectively, for Specimen 1 and 1.22 and $1.17 P_{y}$, respectively, for Specimen 2. 
In Specimen 1, the BRB steadily developed larger forces with larger elongation, minimal

252 kink rotation, and negligible twist and translation of the beam. On the other hand, the BRB in

253 Specimen 2 developed severe out-of-plane deformation after exceeding its predicted buckling

254 strength and yield strength. The figures indicate four time instants when out-of-plane

255 deformation in Specimen 2 increased rapidly. Fig. 11(a) shows that the compressive strength of

256 Specimen 2 reduced after undergoing two substantial compression excursions indicated as Steps

2571 and 3. Fig. 11(b) shows the kink rotation at the top and bottom ends of the BRB, in opposing

258 directions, with the top end developing twice the rotation as the bottom. Residual kink rotation

259 was present after the $70 \%$ motion. The $100 \%$ motion caused a very large residual rotation of 0.22

$260 \mathrm{rad}$. at the top and $0.09 \mathrm{rad}$. at the bottom.

Fig. 11(c) indicates that the kink rotation of the BRB was accompanied by very severe 262 twisting of the beam. Interestingly, the beam twist increased in the same direction when the West 263 BRB developed compression (Steps 1 and 3 in Fig. 11(c)) and when the opposite East BRB 264 developed compression (Steps 2 and 4). Therefore, an important finding from the behavior 265 illustrated in Fig. 11(c) is that the opposite BRB provided little rotational restraint at the BRB-to266 beam intersection and hence did not restrain the buckling deformation. Fig. 11(d) indicates that 267 lateral translation of the beam remained very small (less than $2 \mathrm{~mm}$ over an unbraced length of $2683,000 \mathrm{~mm}$ ) until buckling deformation of the BRB became very evident at Step 2. Figs. 11(c) and

269 (d) suggest that the out-of-plane buckling mode was dominated by the limit case 2 shown in Fig. $2703(\mathrm{c})$. exceeded during the $28 \%$ motion, and increasingly larger out-of-plane deformation was observed during the 28,70 , and $100 \%$ motions. However, no reduction is strength was observed until the 
$100 \%$ motion.

Specimen 2 was subjected to two further motions after the $100 \%$ motion had caused severe buckling deformation of the BRBs. As plastic deformation accumulated in the beam and BRBs during the 100,120 , and $150 \%$ motions, the compressive strength of the BRBs gradually decreased. During the 120 and 150\% motions, the BRBs developed the same tensile strength developed during the $100 \%$ motion. The kink rotation of the BRBs exceeded $0.5 \mathrm{rad}$. at the top end and $0.2 \mathrm{rad}$. at the bottom end. The beam twist angle exceeded $0.35 \mathrm{rad}$. It was observed after the $150 \%$ motion that the mortar was crushed and the steel casing was deformed presumably due to the contact with the transition segment. However, no distress was found in the bracing connections. No fracture was visible in the steel core at the location of severe kinking deformation.

\section{Stability of BRBs}

\section{Test Observations}

The simple buckling model shown in Fig. 1(b) predicted the occurrence of out-of-plane buckling of BRBs in Specimen 2. Buckling deformation was not present until the critical strength $P_{\mathrm{cr}}$ evaluated from Equation (3) and the yield strength $P_{\mathrm{y}}$ was exceeded. The maximum measured $\mathrm{BRB}$ compressive force was $1.68 P_{\mathrm{cr}}$ for the East $\mathrm{BRB}$ and $1.56 P_{\mathrm{cr}}$ for the West $\mathrm{BRB}$.

291 The buckling deformation seen in Fig. 10 and measured deformation in Fig. 11 agree with the

292 prediction that limit case 2 shown in Fig. 3(c) dominates the buckling mode. Consequently, 293 although the prediction was conservative, Equation (3) may be used to estimate the buckling 294 strength for BRBs that meet the five assumptions that justify the buckling model. The local 
damage observed at the edges of the steel casing indicates that appreciable rotational stiffness developed at the ends of the yielding segment as the transition segment bore against the buckling-restraining system. The rotational stiffness, which is neglected in the simple stability model, is believed to be a contributing factor to the increase in buckling strength over the predicted strength $P_{\text {cr. }}$.

Fig. 11(a) suggests that the stable inelastic behavior of BRBs is lost once out-of-plane buckling occurs. On the other hand, Fig. 8 shows that the BRBF maintained appreciable energy dissipation capacity even after the BRBs had buckled. After the BRBs buckled, a large portion of the input energy was dissipated by the underlying moment frame and plastic torsion of the beam, and less substantially by the BRBs. The secondary energy dissipation mechanism of the BRBF and the resiliency of the BRBs should be appreciated. However, considering that severe beam torsion causes significant damage to nonstructural elements and the concrete slab, and makes replacement of BRBs difficult (a serious drawback when the BRBs are implemented as supplemental energy dissipation devices), the out-of-plane buckling deformation of BRBs demonstrated in Specimen 2 should be avoided.

\section{Effect of Imperfection}

A question remains as to how out-of-plane stability of BRBs is affected by inherent imperfection and story drifts in the orthogonal loading direction. The question may be addressed by a modified buckling model shown in Fig. 3(d) where assumption (5) is removed. In the figure, $\theta_{10}, \theta_{20}$, and $u_{0}$ denote imperfections that are present under zero force $(P=0)$. For the modified model, the equilibrium condition leads to the following relationship between the BRB compression $P$, deformation $\theta_{1}$, and imperfections $\theta_{10}$ and $u_{0}$. 


$$
\left(\theta_{1}+\theta_{10}\right) P^{2}-\left[\left(\theta_{1}+\theta_{10}\right)\left(1+\frac{L_{1}}{L_{2}}\right) P_{H}+\theta_{1} P_{R}+\frac{P_{H}}{L_{2}} u_{0}\right] P+\theta_{1} \cdot P_{H} P_{R}=0
$$

Fig. 12 plots the relationship between the BRB compression and $\left(u+u_{0}\right),\left(\theta_{1}+\theta_{10}\right)$, and $\left(\theta_{2}+\theta_{20}\right)$, given the properties of Specimen 2 , and assuming initial drift ratios ( $u_{0}$ divided by the story height $2.1 \mathrm{~m}$ ) of 0.002 to $0.02 \mathrm{rad}$. and $\theta_{1}=0$. Deformation increases as $P$ asymptotically approaches the critical strength $P_{\mathrm{cr}}=197 \mathrm{kN}$. Although the plotted loading paths do not represent response to earthquake ground motions, Fig. 12 demonstrates how the critical strength reduces with out-of-plane deformation. An initial drift ratio of 0.002 rad., which is representative of construction tolerance, has a minor effect on the strength and stability of the BRBs. However, an out-of-plane drift of 0.02 rad., which is the prescribed design drift limit under seismic loads (ASCE 2005), leads to large out-of-plane deformation at $P=0.75 P_{\mathrm{cr}}$.

\section{Bracing Requirements at the BRB-to-beam intersection}

Fig. 12 plots the compression versus deformation relationships for the case with an initial drift ratio of $0.02 \mathrm{rad}$. and $P_{2}$ doubled from that was provided in Specimen 2. The figure suggests that, even against a large initial out-of-plane story drift of $0.02 \mathrm{rad}$, amplification of the initial deformation can be contained well by doubling $P_{2}$. As observed by Kinoshita et al. (2007) and Koetaka and Kinoshita (2009), $P_{c r}$ nearly equals $P_{2}$ (i.e., $P_{c r}$ is controlled primarily by $K_{R}$ while $K_{H}$ plays a minor role) for regularly proportioned chevron BRBFs that are not laterally braced at the BRB-to-beam intersection. Therefore, out-of-plane stability of the BRB may be controlled by designing $P_{2}$ to be at least twice as large as the maximum expected BRB force, $P_{0}$. In other words the required stiffness of the torsional bracing may be expressed as follows: 


$$
K_{R} \geq 2 P_{0} \frac{L_{1}\left(L_{1}+L_{2}\right)}{L_{2}}
$$

336 If such $P_{2}$, or equivalently $K_{R}$, is not supplied by the beam, then adequate torsional bracing must 337 be provided at the BRB-to-beam intersection.

\section{Conclusions}

Large-scale shake table tests were conducted to study the out-of-plane stability of BRBs placed in a chevron arrangement. Two chevron BRBF specimens were repeatedly subjected to a unidirectional ground motion with increasing amplification. No lateral bracing was provided at the BRB-to-beam intersection to promote out-of-plane instability of the BRBs. The BRBs in Specimen 2 had an unusually short embedment length of the transition segment inside the steel casing. A buckling model, which is a simplification of a model previously proposed in the Japanese literature, was used to predict the out-of-plane buckling strength of BRBs. Key findings from this study are summarized in the following.

1) The BRBs in Specimen 1 had the transition segment embedded inside the steel casing to 1.5 times the depth of the yielding segment, as suggested by Takeuchi et al. (2009). As expected, the BRBs did not buckle and Specimen 1 exhibited excellent seismic behavior. This result validates the suggestion by Takeuchi et al.

2) The BRBs in Specimen 2 adopted a very short embedment length of the steel projection inside the steel casing. This specimen exhibited excellent behavior until the BRBs failed due to out-of-plane buckling. As predicted by the buckling model, the buckling mode involved kinking deformation at both ends of the BRBs and twisting of the beam at the 
BRB-to-beam intersection.

3) The measured BRB compression in Specimen 2 exceeded the predicted critical strength by 56 to $68 \%$ and exceeded the yield strength by 17 to $26 \%$. The buckling model provides a conservative estimate of the critical strength presumably because the model neglects the flexural stiffness of the yielding segment caused by bearing of the transition segment against the steel casing and mortar.

4) The resiliency of BRBs enabled stable energy dissipation of Specimen 2 even as the buckling deformation progressed to an extreme extent. Nonetheless, considering the damage expected to nonstructural elements and the concrete slab caused by beam twisting, out-of-plane buckling is not a preferred limit state for BRBs.

5) The buckling model can be extended to incorporate out-of-plane imperfection and story drift. The model may be used to estimate the minimal lateral bracing requirements for chevron BRBFs.

\section{Acknowledgement}

The project presented in this paper was funded by the National Research Institute for Earth Science and Disaster Prevention (NIED) of Japan. Naomiki Suzuki and Makoto Ohsaki provided guidance to the overall project and specimen design. The authors thank Toru Takeuchi and Yuji Koetaka for sharing their views and latest research findings. Sachi Furukawa, Ryo Umehara, and Xuchuan Lin helped processing the data. The BRBs were provided by Nippon Steel Engineering Co., Ltd. Maekawa Co., Ltd. managed specimen fabrication and construction of the test setup. Special thanks are extended to the administrative and technical staff of E- 
Defense, officially named the Hyogo Earthquake Engineering Research Center. The opinions expressed in this paper are those of the authors and do not necessarily reflect the views of the individuals and organizations mentioned above.

\section{Appendix: Critical loads derived by Kinoshita et al. (2007)}

Fig. 1(c). The original expressions are modified to match the expressions adopted in Equation (3).

$$
\begin{aligned}
& \left(P-\overline{P_{H}}\right)\left(P-\overline{P_{R}}\right)-P \cdot \overline{P_{X}}=0 \\
& \cos \left(\xi \alpha_{\mathrm{tr}}\right)-2 \frac{\sin \left(\xi \alpha_{\mathrm{tr}}\right)}{\alpha_{\mathrm{tr}}}=0 \\
& \cos \left(\xi \alpha_{\mathrm{tr}}\right)=0
\end{aligned}
$$

382 The three equations correspond to the three buckling modes indicated in Fig. 1(c). The notations

383 shown in Fig. 1(c) are used, where $\xi$ is the length ratio between the stiffened segment (core

384 projection plus transition segment) and the entire BRB, and:

$$
\alpha_{\mathrm{tr}}=L \sqrt{\frac{P}{E I_{\mathrm{tr}}}}
$$

385 where $E I_{\text {tr }}$ is the elastic bending stiffness of the stiffened segment (see Fig. 1(c)). Further:

$$
\overline{P_{H}}=K_{H} \cdot L \frac{\cos \left(\xi \alpha_{\mathrm{tr}}\right)-2 \frac{\sin \left(\xi \alpha_{\mathrm{tr}}\right)}{\alpha_{\mathrm{tr}}}}{\cos \left(\xi \alpha_{\mathrm{tr}}\right)}
$$




$$
\begin{aligned}
& \overline{P_{R}}=K_{R} \cdot \frac{\cos \left(\xi \alpha_{\mathrm{tr}}\right)}{d^{*} \cdot \cos \left(\xi \alpha_{\mathrm{tr}}\right)+L \frac{\sin \left(\xi \alpha_{\mathrm{tr}}\right)}{\alpha_{\mathrm{tr}}}} \\
& \overline{P_{X}}=K_{H}\left(d^{*} \cdot \cos \left(\xi \alpha_{\mathrm{tr}}\right)+L \frac{\sin \left(\xi \alpha_{\mathrm{tr}}\right)}{\alpha_{\mathrm{tr}}}\right)
\end{aligned}
$$

386 By taking $E I_{\mathrm{tr}} \rightarrow \infty$ in the above equations, $\alpha_{\mathrm{tr}} \rightarrow 0$, and thus, $\overline{P_{H}} \rightarrow P_{H}, \overline{P_{R}} \rightarrow P_{R}$, and $\overline{P_{X}} \rightarrow$

$387 P_{H}\left(L_{1} / L_{2}\right)$. Therefore, when elastic deformation of the gusset plates is neglected, Equation (9a)

388 reduces to Equation (3). On the other hand, Equations (9b) and (9c) are buckling loads that are

389 associated with elastic deformation of the gusset plates, and which cannot be captured by the

390 model adopted in the current study. Using the dimensions of Specimen 2 and $P=197 \mathrm{kN}, \alpha_{\mathrm{tr}}=$

$3910.0446, \xi \alpha_{\mathrm{tr}}=0.0105$, and therefore, Equations (3) and (9a) result in the same solution for

392 engineering purposes. 


\section{References}

American Institute of Steel Construction, Inc. (AISC). (2005a). Seismic Provisions for Structural Steel Buildings. ANSI/AISC Standard 341-05. AISC, Chicago, Illinois.

American Institute of Steel Construction, Inc. (AISC). (2005b). Specification for Structural Steel Buildings. ANSI/AISC Standard 360-05. AISC, Chicago, Illinois.

American Society of Civil Engineers (ASCE). (2005). Minimum Design Loads for Buildings and Other Structures. ASCE/SEI 7-05. ASCE, Reston, Virginia.

Architectural Institute of Japan (AIJ), (2009). Recommendation for Stability Design of Steel Structures, Maruzen, Tokyo, Japan, (in Japanese).

Black, C.J., Makris, N., and Aiken, I.D. (2004). "Component testing, seismic evaluation and characterization of buckling-restrained braces.” Journal of Structural Engineering, ASCE, 130(6), 880-894.

Building Center of Japan (BCJ). (2007). Article 82(5.3), Enforcement Ordinance of Construction Standard Law, Ministry of Land, Infrastructure, Transport, and Tourism, Japan (in Japanese).

Chou, C.-C. and Chen, Pi-J. (2009). "Compressive behavior of central gusset plate connections for a buckling-restrained braced frame.” Journal of Constructional Steel Research, 65, $1138-1148$.

Fahnestock, L.A., Sause, R., and Ricles, J.M. (2007). "Seismic response and performance of buckling-restrained brace frames.” Journal of Structural Engineering, ASCE, 133(9), 
1195-1204.

Kinoshita, T., Koetaka, Y., Inoue, K., and Iitani, K. (2007). “Criteria of buckling-restrained braces to prevent out-of-plane buckling." Journal of Structural and Construction Engineering, Architectural Institute of Japan, 621, 141-148, (in Japanese).

Kinoshita, T., Koetaka, Y., Inoue, K., and Iitani, K. (2008). "Out-of-plane stiffness and yield strength of cruciform connection for buckling-restrained brace.” Journal of Structural and Construction Engineering, Architectural Institute of Japan, 632, 1865-1873, (in Japanese).

Koetaka, Y. and Kinoshita, T. (2009). "Design criteria of buckling-restrained brace to prevent out-of-plane buckling." Journal of Structural and Construction Engineering, Architectural Institute of Japan, 641, 1371-1378, (in Japanese).

Mahin, S., Uriz, P., Aiken, I., Field, C., and Ko, E. (2004). "Seismic performance of buckling restrained braced frame systems." 13th World Conference on Earthquake Engineering, Paper No. 1681, Vancouver, British Columbia, Canada, August 1-6, 2004.

Nakamura, Y., Uehan, F., and Inoue, H. (1996). "Waveform and its analysis of the 1995 Hyogoken-Nanbu Earthquake II.” JR Earthquake Information No. 23d, UrEDAS R\&D Promotion Department, Railway Technical Research Institute, Tokyo, Japan, (in Japanese).

Nakashima, M., Roeder, C.W., and Maruoka, Y. (2000). "Steel moment frames for earthquakes in United States and Japan.” Journal of Structural Engineering, ASCE, 126(8), 861-868. 
Roeder, C.W., Lehman, D.E., and Christopulos, A. (2006). "Seismic performance of special concentrically braced frames with buckling restrained braces." 8th U.S. National Conference on Earthquake Engineering, San Francisco, California, April 18-22, 2006, Paper No. 1503.

Saeki, E., Maeda, Y., Nakamura, H., Midorikawa, M., and Wada, A. (1995). "Experimental study on practical-scale unbounded braces.” Journal of Structural and Construction Engineering, Architectural Institute of Japan, 476, 149-158, (in Japanese).

Takeuchi, T., Yamada, S., Kitagawa, M., Suzuki, K., and Wada, A. (2004). "Stability of buckling-restrained braces affected by the out-of-plane stiffness of the joint element." Journal of Structural and Construction Engineering, Architectural Institute of Japan, 575, 121-128, (in Japanese).

Takeuchi, T., Kasai, K., Midorikawa, M., Matsuoka, Y., Asakawa, T., Kubodera, I., Kurokawa, Y., Kishiki, S., and Ando, H. (2008). "Shaking table test using E-Defense multipurpose test bed." 14th World Conference on Earthquake Engineering, Beijing, China, October 12-17, 2008.

Takeuchi, T., Matsui, R., Nishimoto, K., Takahashi, S., and Ohyama, T. (2009). "Effective buckling length for buckling restrained braces considering rotational stiffness at restrainer ends." Journal of Structural and Construction Engineering, Architectural Institute of Japan, 639, 925-934, (in Japanese).

Tembata, H., Koetaka, Y., and Inoue, K. (2004). “Out-of-plane buckling load of bucklingrestrained braces including brace joints." Journal of Structural and Construction 
Engineering, Architectural Institute of Japan, 581, 127-134, (in Japanese).

Uang, C.-M. and Nakashima, M. (2004). "Steel buckling-restrained braced frames.” Earthquake Engineering from Engineering Seismology to Performance Based Engineering, Chapter 16, Y. Bozorgnia and V.V. Bertero (eds.), CRC Press, Boca Raton, Florida. 


\section{List of Tables}

Table 1 Measured material properties

Table 2 Scaling rule

Table 3 Excitation levels 


\section{List of Figures}

Fig. 1 Out-of-plane stability model: (a) chevron brace; (b) model for standard connections; (c) model proposed by Kinoshita et al. (2007); and (d) model for alternative conditions.

Fig. 2 Bracing connection details: (a) standard 1; (b) standard 2; and (c) alternative.

Fig. 3 Buckling modes: (a) general mode; (b) limit case 1; and (c) limit case 2.

Fig. 4 Condition to achieve $P_{c r}=P_{0}$

Fig. 5 Test specimen: (a) elevation and out-of-plane bracing points; (b) BRBs in Specimen 1; and (c) BRBs in Specimen 2. (Dimensions in $\mathrm{mm}$ ).

Fig. 6 Specimen and test-bed system

Fig. 7 Response spectra for JR Takatori EW motion

Fig. 8 Frame response at: (a) 100\% motion; and (b) 120\% motion.

Fig. 9 (a) Maximum drift; and (b) residual drift, recorded at end of each motion.

Fig. 10 Specimen 2 after 120\% motion: (a) side view; and (b) close-up view.

Fig. 11 BRB response at 100\% motion: (a) BRB elongation; (b) BRB kink rotation; and (c) beam twist angle.

Fig. 12 Out-of-plane deformation induced by initial imperfection 
Table $1 \quad$ Measured material properties

\begin{tabular}{ccccc}
\hline Material & JIS designation & $\begin{array}{c}\text { Yield strength } \\
(\mathrm{MPa})\end{array}$ & $\begin{array}{c}\text { Tensile strength } \\
(\mathrm{MPa})\end{array}$ & $\begin{array}{c}\text { Elongation } \\
(\%)\end{array}$ \\
\hline Steel core $(12 \mathrm{~mm})$ & SN400B & 297 & 421 & 35 \\
Beam flange $(9 \mathrm{~mm})$ & SN400B & 327 & 456 & 27 \\
Beam web $(6 \mathrm{~mm})$ & SN400B & 376 & 472 & 29 \\
Column $(9 \mathrm{~mm})$ & BCR295 & 434 & 518 & 19 \\
Gusset plate $(12 \mathrm{~mm})$ & SM490A & 315 & 441 & 32 \\
\hline
\end{tabular}


Table 2 Scaling rule

\begin{tabular}{ccc}
\hline Parameters & \multicolumn{2}{c}{ Scaling Factor } \\
\hline Length & $\lambda$ & 0.7 \\
Mass & $\lambda$ & 0.7 \\
Acceleration & $\lambda$ & 0.7 \\
Time & 1 & 1 \\
Force & $\lambda^{2}$ & 0.5 \\
Velocity & $\lambda$ & 0.7 \\
Stress & 1 & 1 \\
\hline
\end{tabular}


Table 3 Excitation levels

\begin{tabular}{ccccc}
\hline \multirow{2}{*}{$\begin{array}{c}\text { Target } \\
\text { Amplification }\end{array}$} & \multicolumn{2}{c}{ Specimen 1 } & \multicolumn{2}{c}{ Specimen 2 } \\
\cline { 2 - 5 }$\left(\mathrm{m} / \mathrm{s}^{2}\right)$ & $\begin{array}{c}\text { Mveraged RSA } \\
\left(\mathrm{m} / \mathrm{s}^{2}\right)\end{array}$ & $\begin{array}{c}\text { Max. acc. } \\
\left(\mathrm{m} / \mathrm{s}^{2}\right)\end{array}$ & $\begin{array}{c}\text { Averaged RSA } \\
\left(\mathrm{m} / \mathrm{s}^{2}\right)\end{array}$ \\
\hline $14 \%$ & 1.21 & 4.8 & 1.16 & 4.6 \\
$21 \%$ & 1.54 & 6.6 & - & - \\
$28 \%$ & 1.99 & 8.6 & $2.06 / 2.09$ & $9.0 / 9.2$ \\
$42 \%$ & 3.45 & 16 & - & - \\
$56 \%$ & 4.40 & 20 & - & - \\
$70 \%$ & 4.43 & 20 & 4.48 & 20 \\
$84 \%$ & 5.58 & 25 & - & - \\
$100 \%$ & 6.78 & 30 & 6.77 & 30 \\
$120 \%$ & 7.98 & 35 & 8.40 & 38 \\
$150 \%$ & - & - & 10.2 & 46 \\
\hline
\end{tabular}




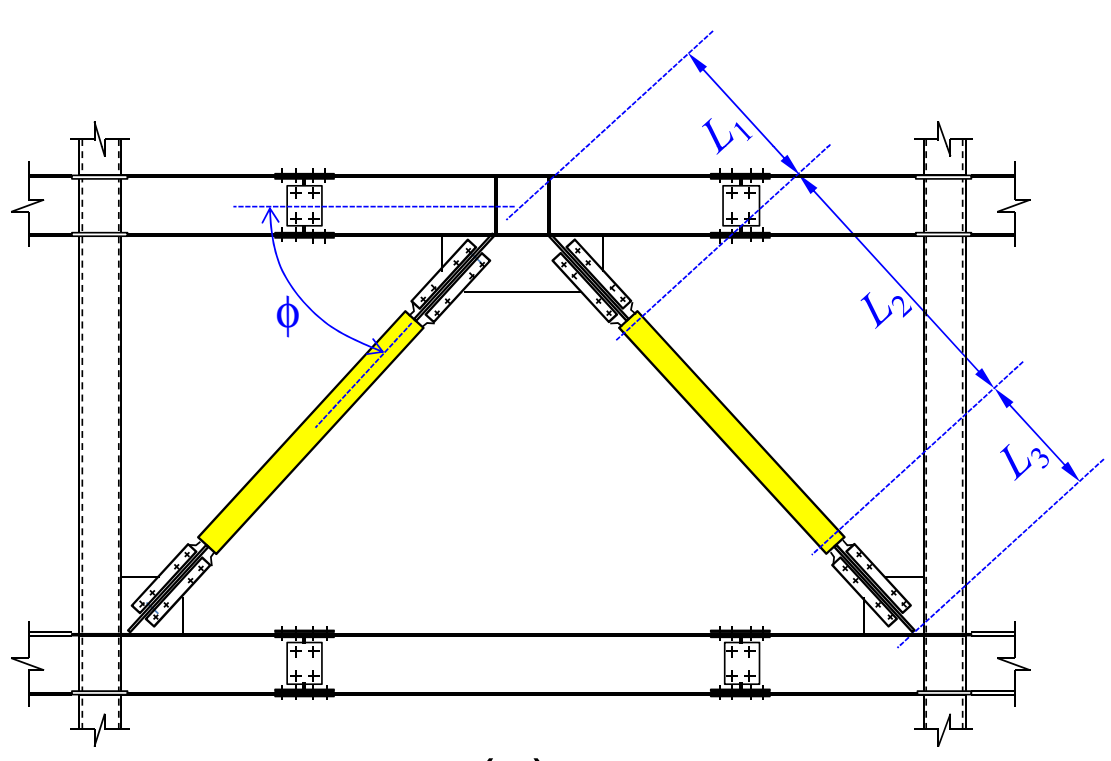

(a)

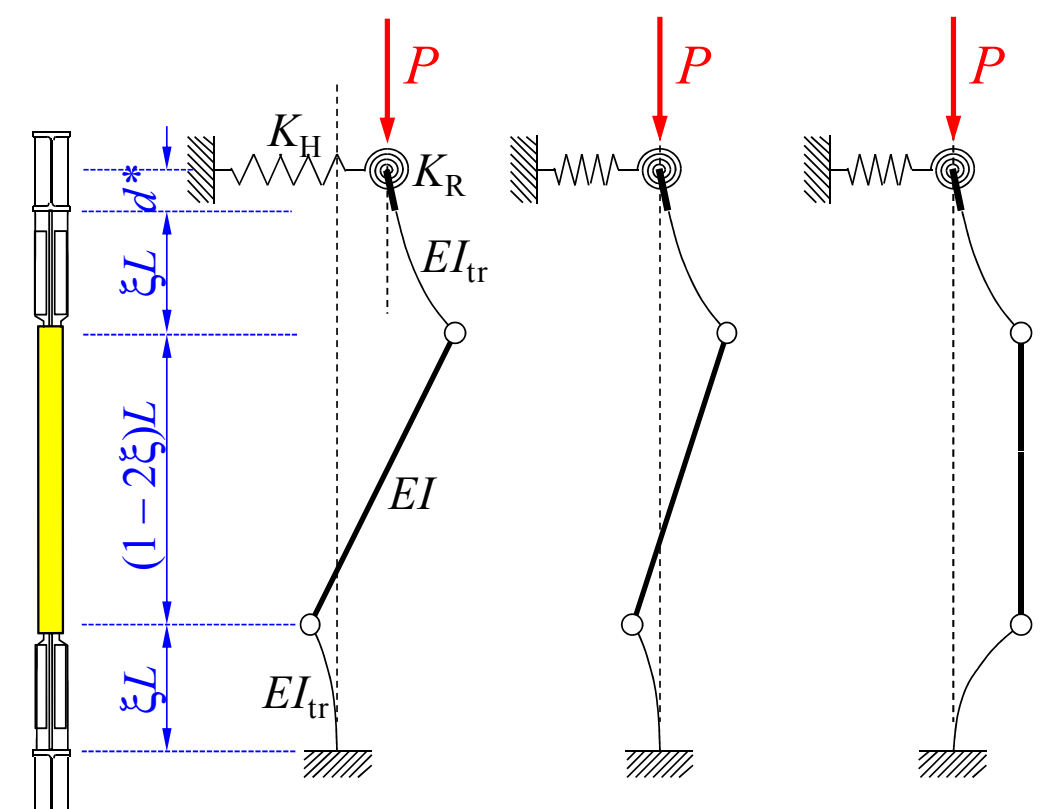

(c)

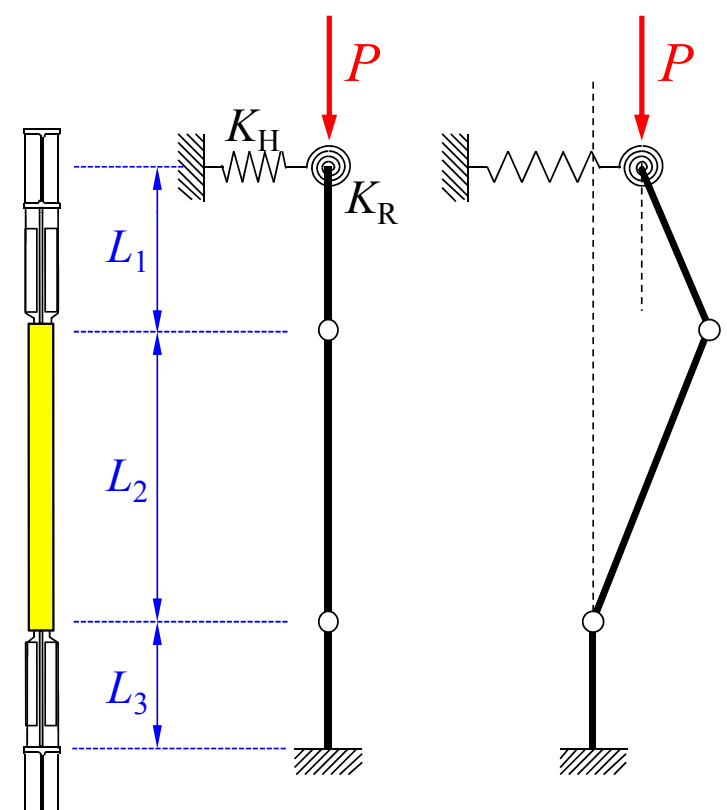

(b)

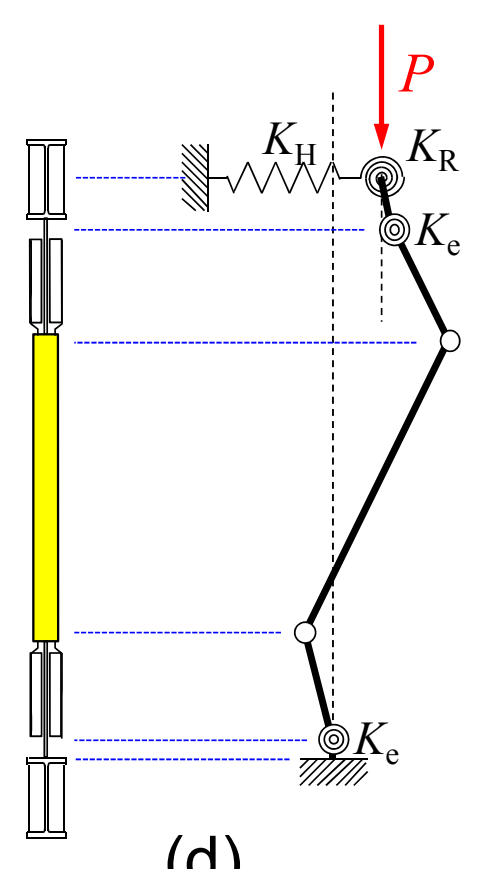

(d) 


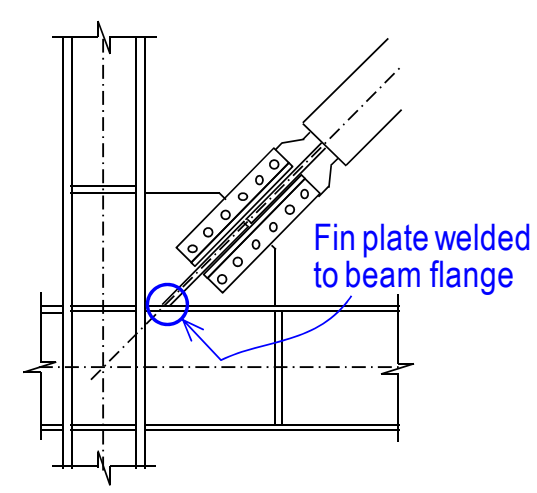

(a)

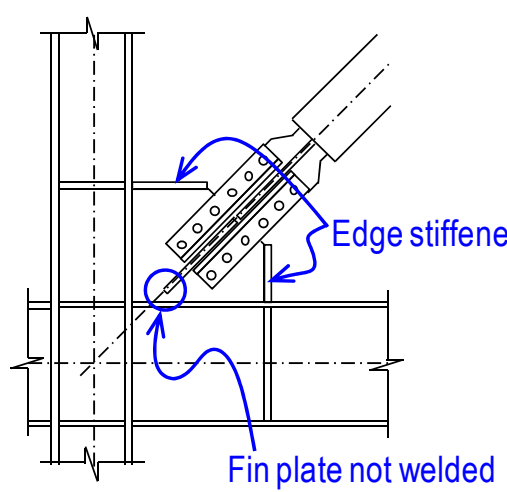

(b)

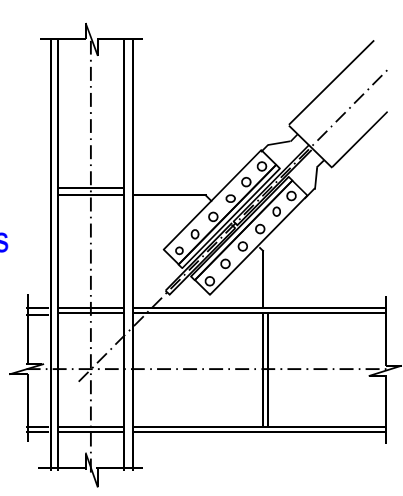

(c) 


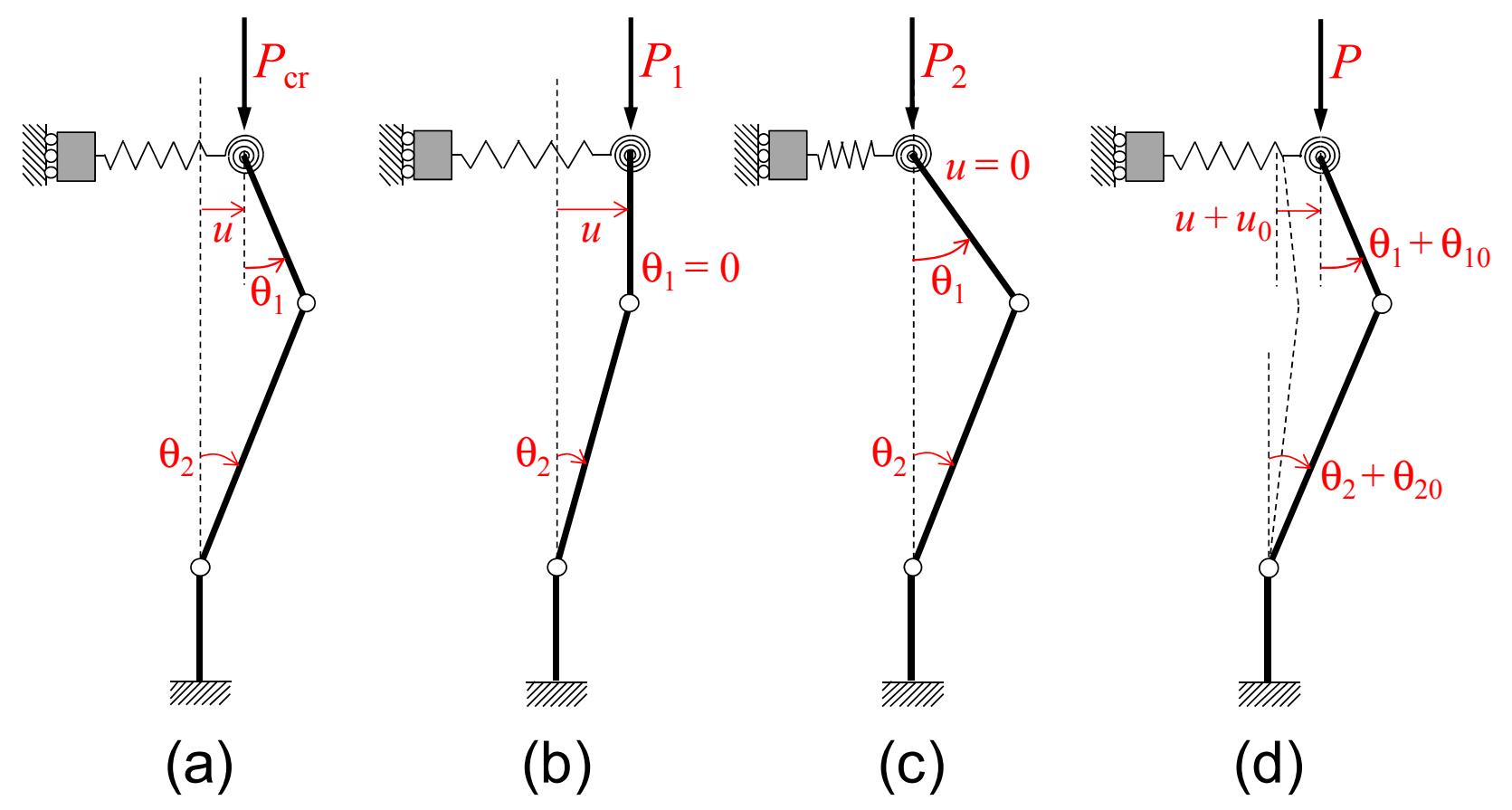




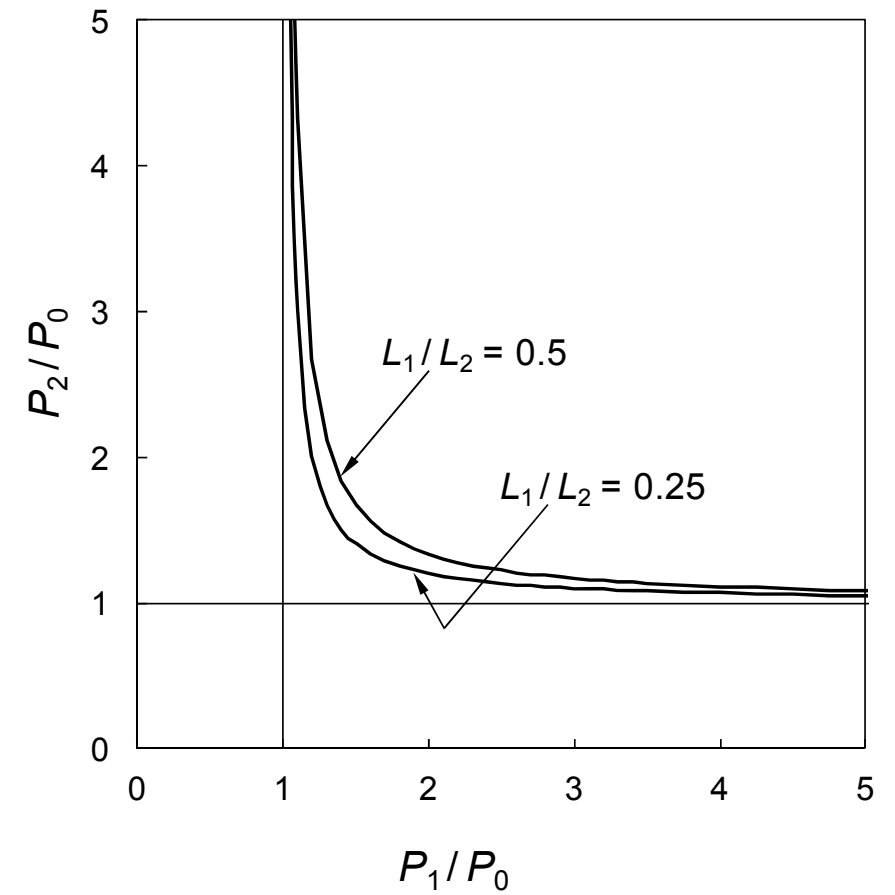



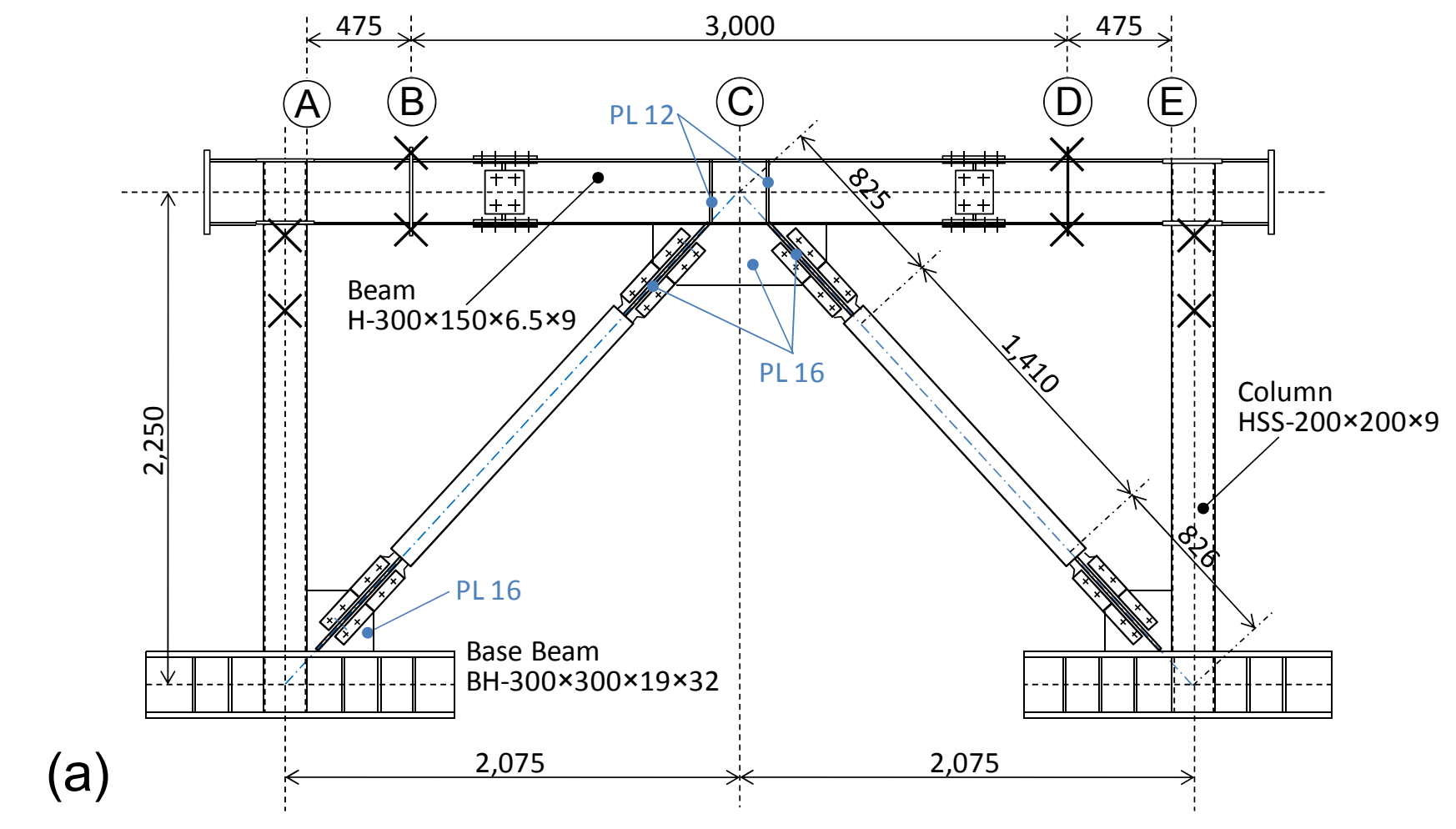

(b)

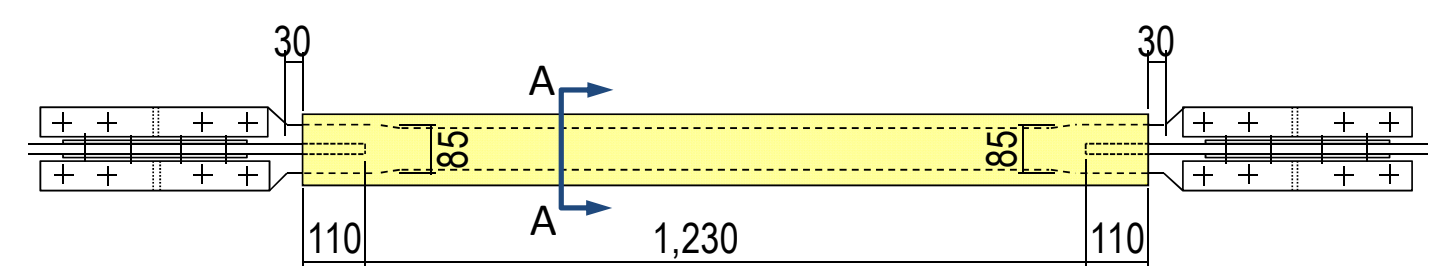

(c)

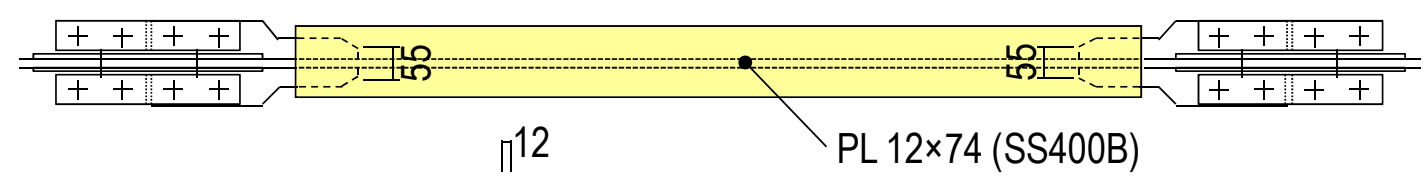

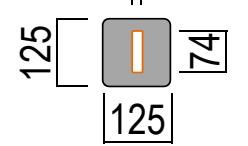
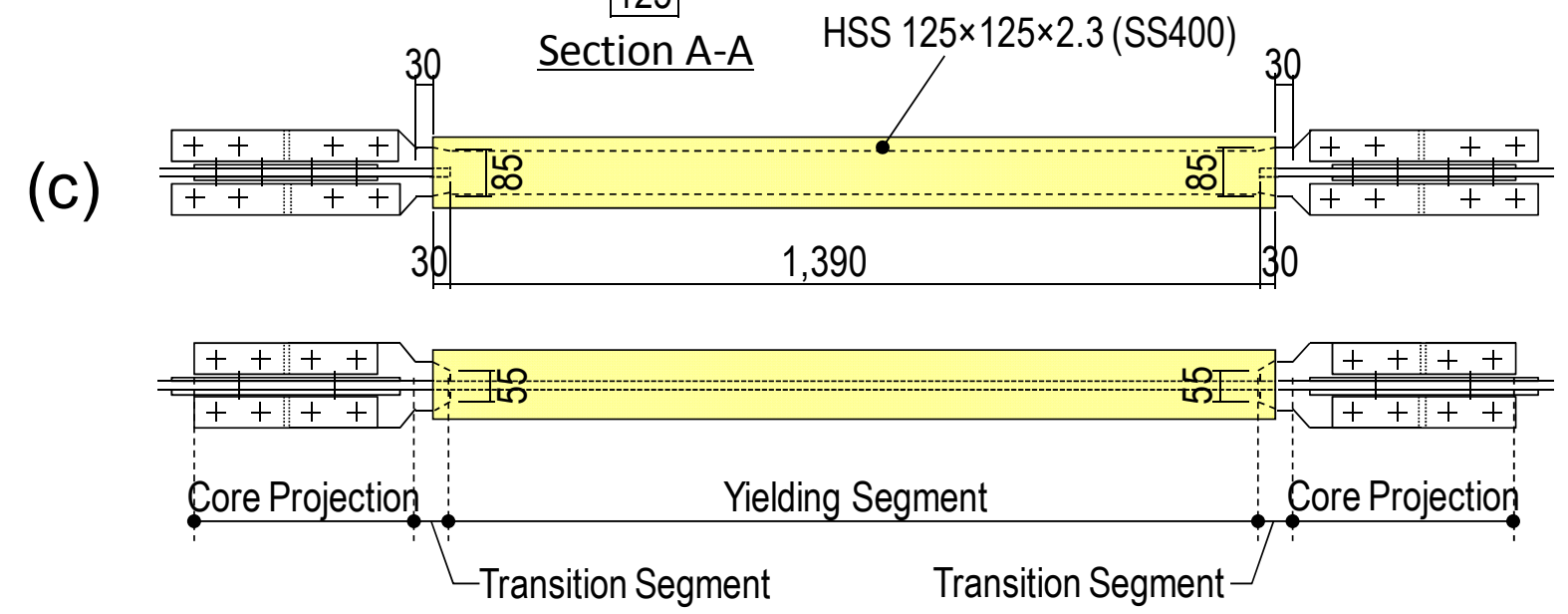


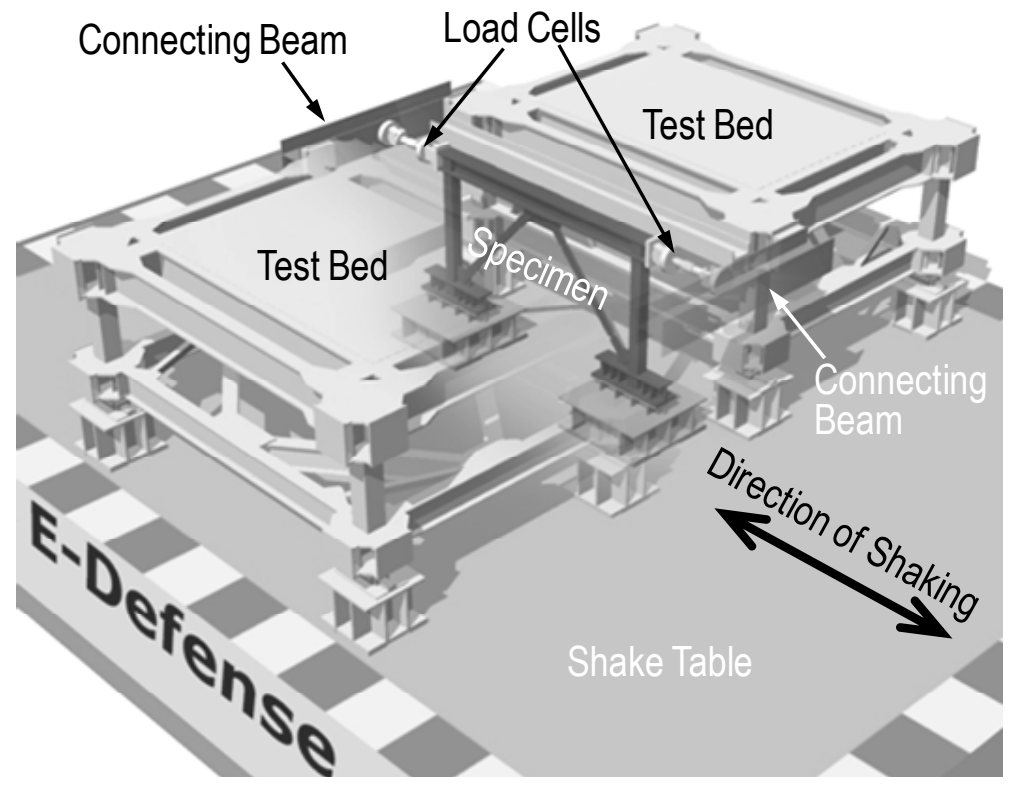




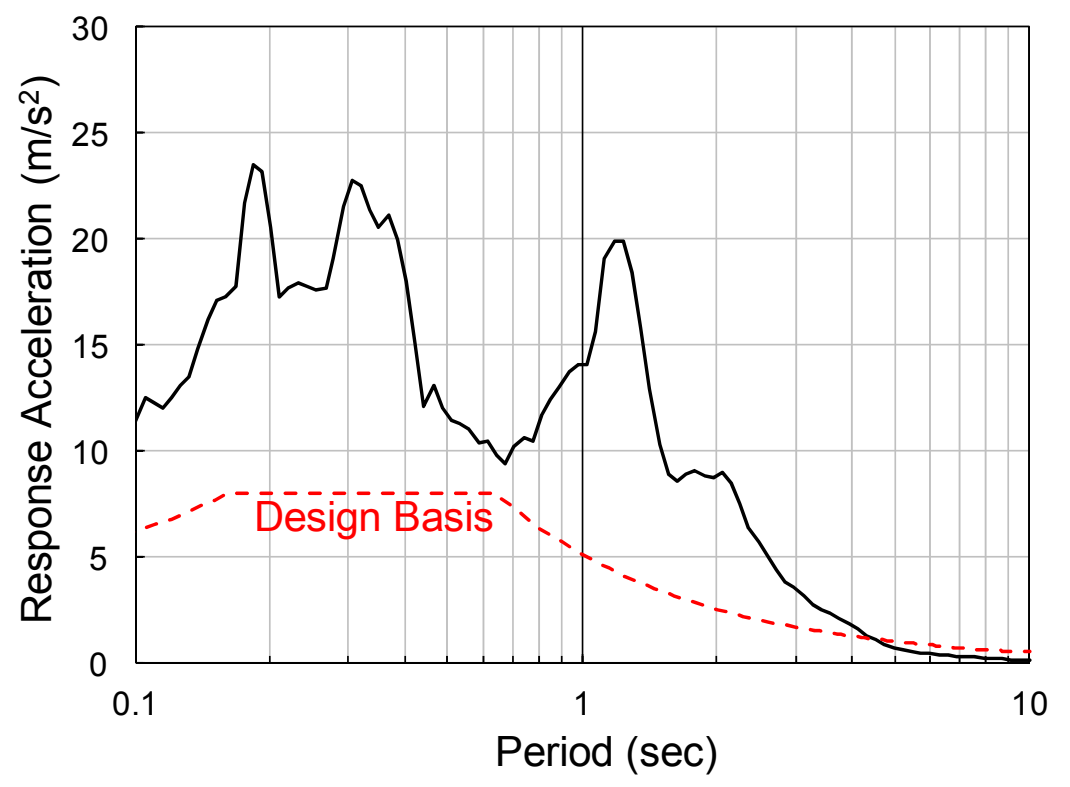



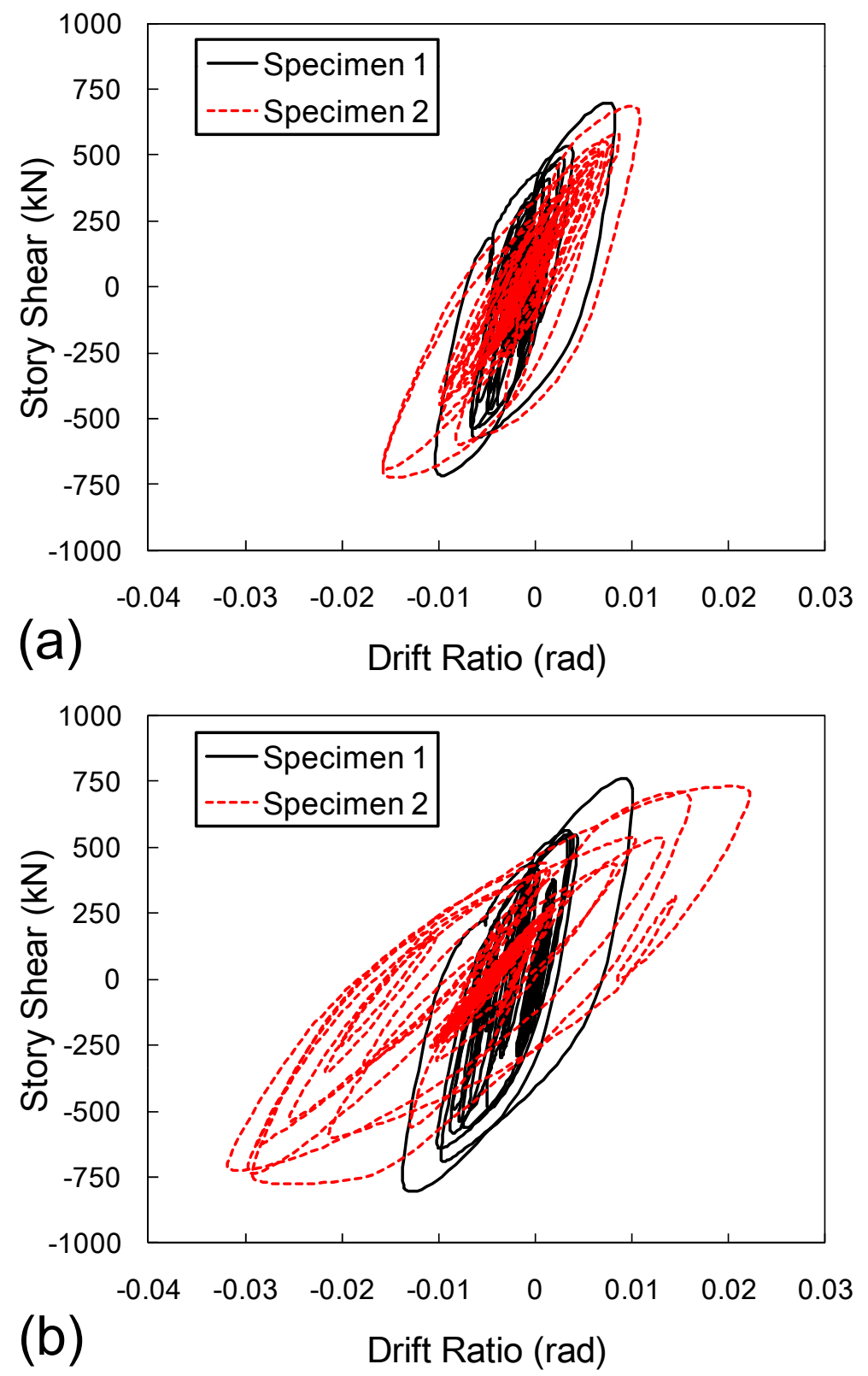


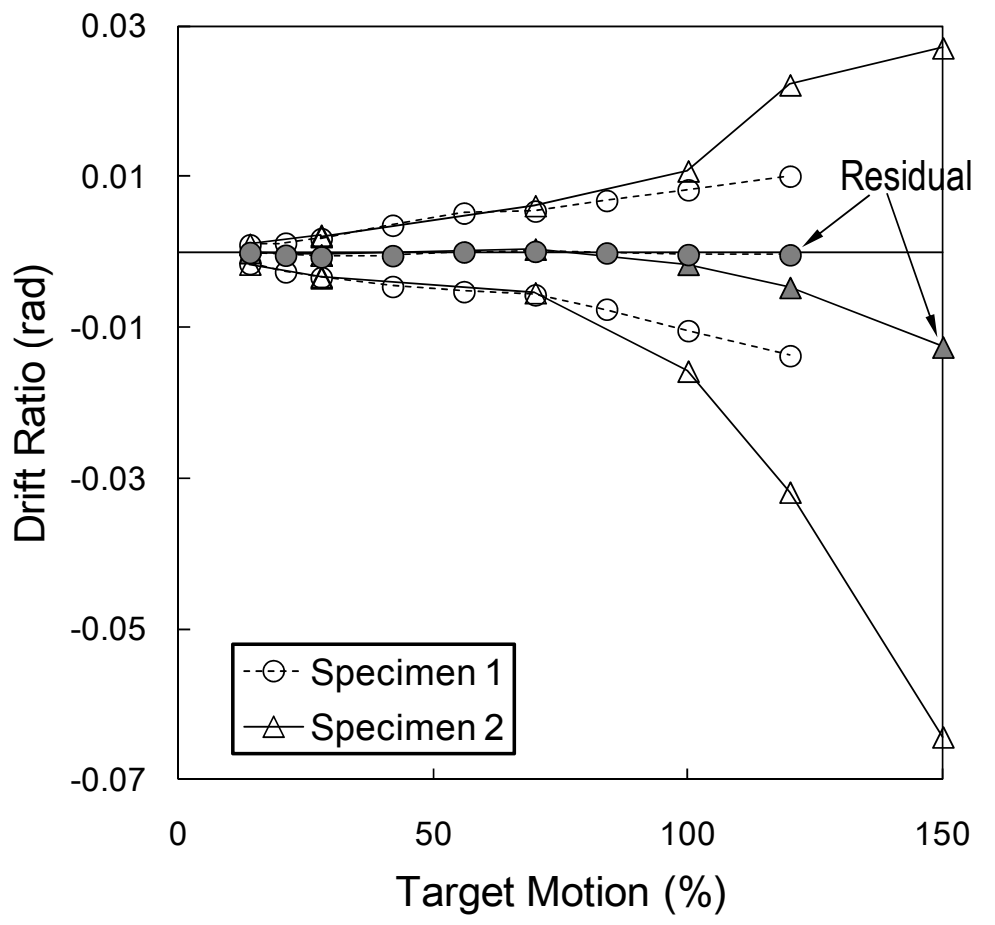



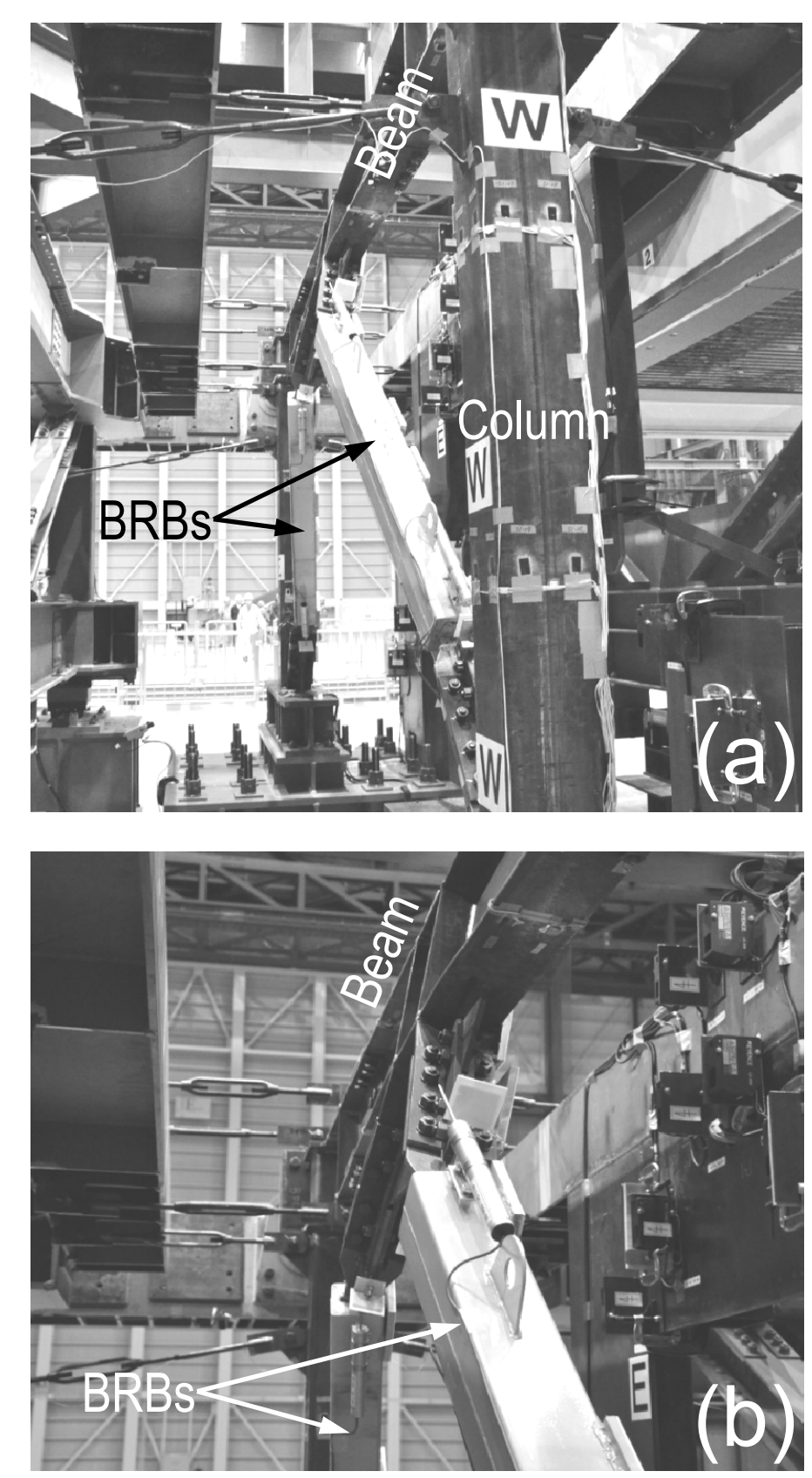


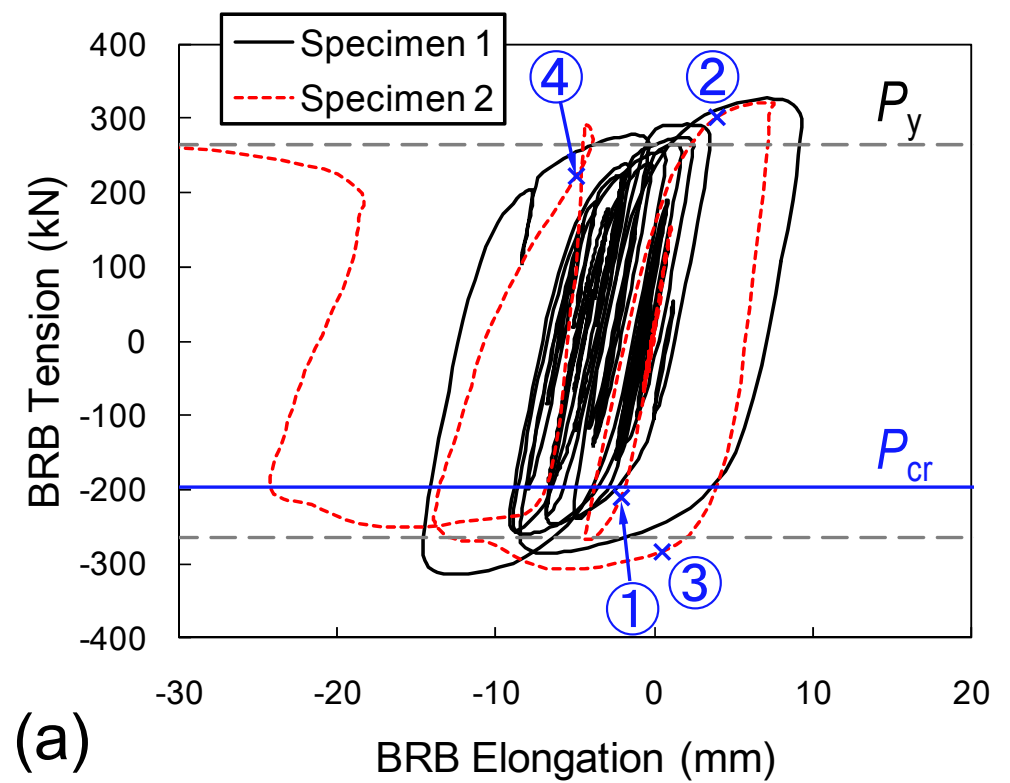




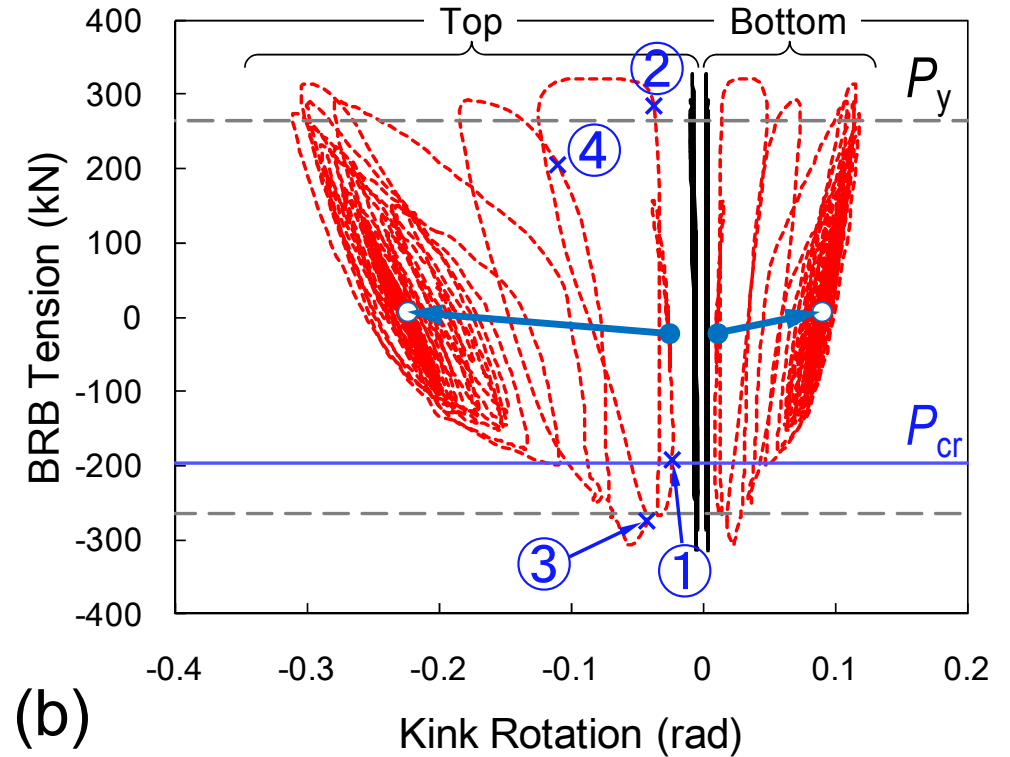




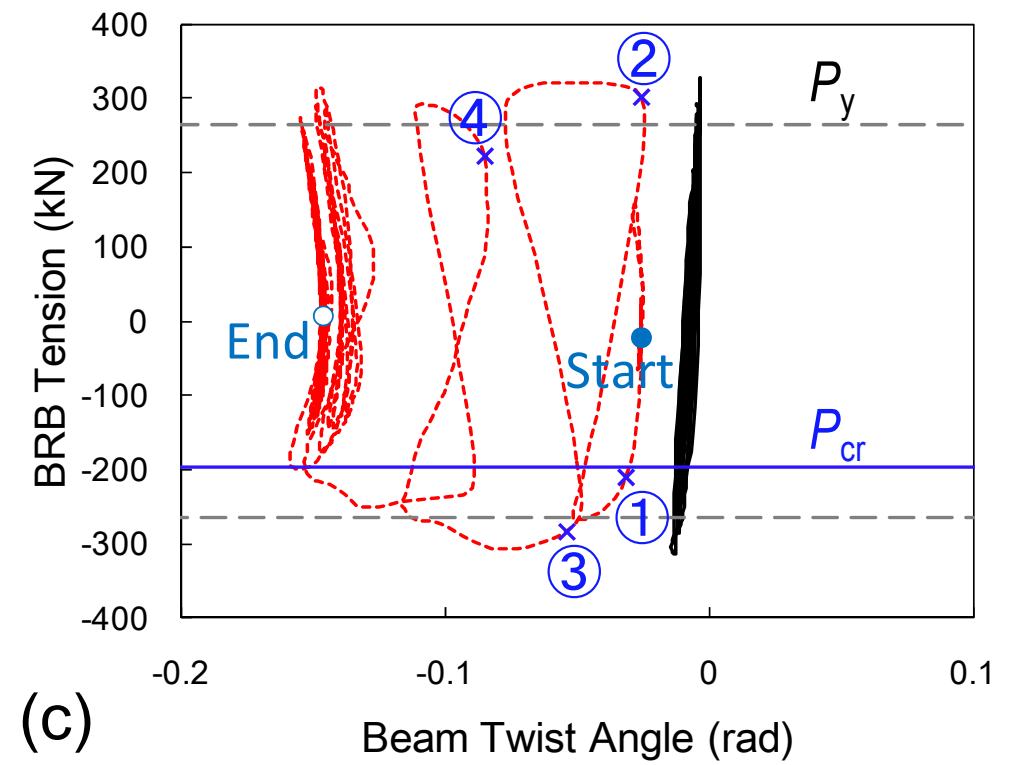




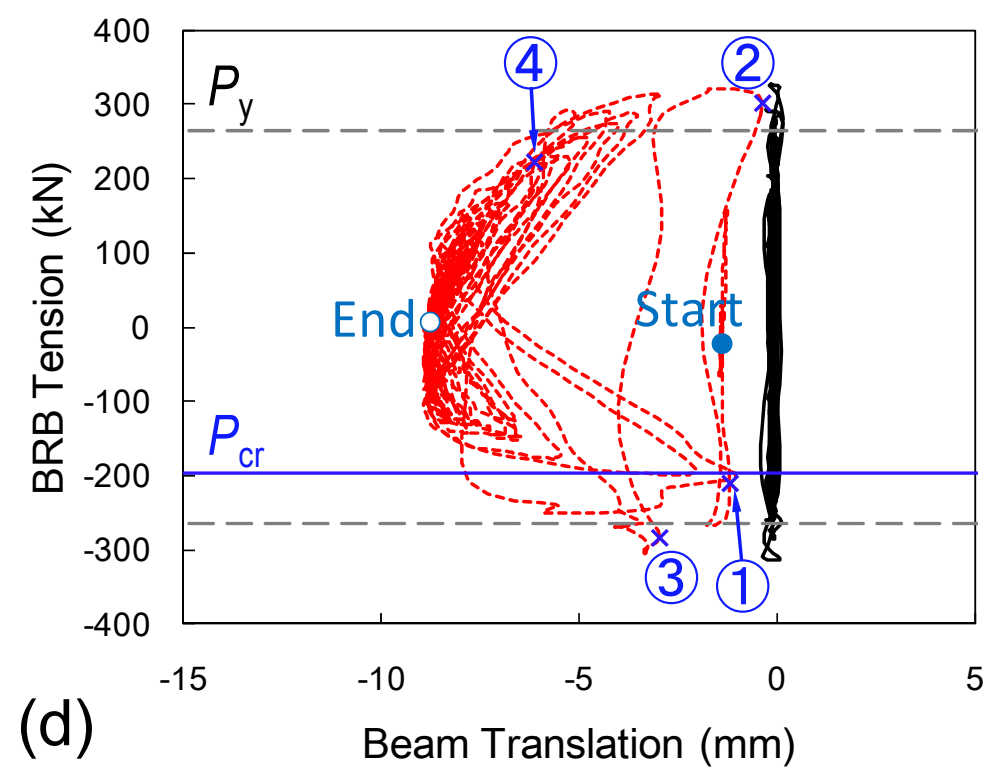



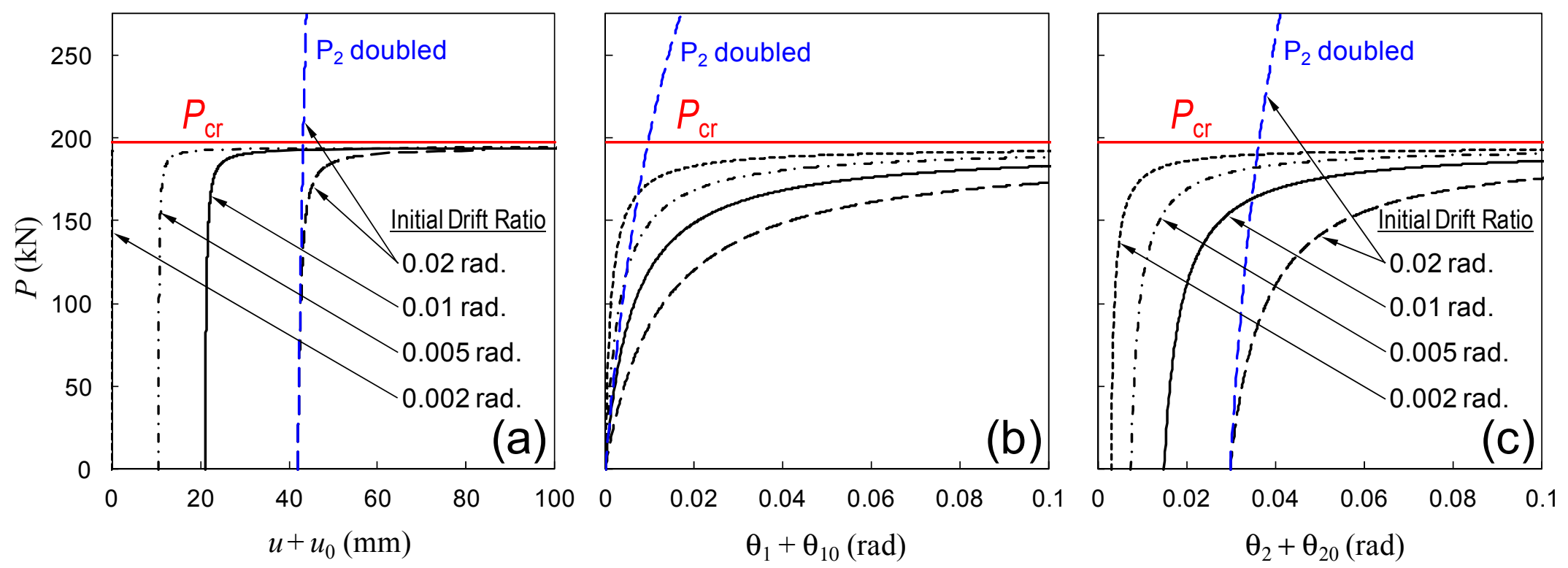